\title{
Biofuel: A Tool for Addressing the Rapid Needs for Sustainable Development
}

\author{
Shrota Shrestha ${ }^{1} \&$ Shambhu Paudel ${ }^{2}$
}

\begin{abstract}
The energy crisis, climate change and global warming and the impending food crisis are interlinked issues, which are threatening the prosperity, solidarity, and demand of the people and also their existence. Immense network of protected areas for the protection of biodiversity are still affected at this tenure due to such linkage, which is crucial and targeted issues of global community.Petrolium product are being gift for the people of Kathmandu valley from their relatives living in terai, at this moment.Nowdays, biofuels can be product for addressing rapid needs of urban people. The use of biomass fuels can therefore contribute to waste management as well as fuel security and help to prevent climate change, though alone they are not a comprehensive solution to these problems. For the sustainable production of biofuel, policies and plan of the region should be reformed. It needs further exploration for optimum in the region.
\end{abstract}

Key Words: Rapid, Biological, Sustainable, Poverty, Biofuel

\section{Introduction}

Biofuel can be broadly defined as solid, liquid, or gas fuel derived from recently dead biological material.Biofuel can be theoretically produced from any (biological) carbon source, though the most common by far is photosynthetic plant. Biofuel is more nearly carbon neutral and less likely increase atmospheric concentrations of greenhouses gases. While fossil fuels which return carbon which was stored beneath the surface for millions of years into the air. There are some types $^{3}$ : first generation (biofuels made from sugar, starch, vegetables oil, or animals oil using conventional technology.e.g. vegetable oil, bio alcohol, bio diesel, bio gas), Second generation biofuels (from non food crops, including cellulosic biofuels),third generation biofuels (from algae, also called oilgae).

A biofuel is difficult to define. Most of the fossil fuels we use are biological in nature. Perhaps we have to say that a biofuel is one that does not add to the stock of total carbon dioxide in the atmosphere. These are plant forms that, typically, remove carbon dioxide from the atmosphere, and give up the same amount when burnt. Naturally, all the other fossil fuels have done the same, but we are talking about a time scale of one or two years for the biofuels, whereas the

\footnotetext{
Kathmandu Forestry College, Kathmandu, Nepal,shr_173@yahoo.com

2 Kathmandu Forestry College, Kathmandu, Nepal, oasis.excurrent@gmail.com

UN, Biofuel Reports 2001
} 
fossil fuels can only be considered on a time scale measured in millions of years. The biofuels are therefore considered to be " $\mathrm{CO}_{2}$ neutral", not adding to the carbon dioxide level in the atmosphere. The type of biofuel used will depend on a number of factors, chief amongst them being the available feedstock and the energy that can be used locally.

\section{Biofuel Scenario in Nepal}

Petroleum products nowadays are being scarce due to the inflation of the global community market. Behind this, there are many associates' problems which are the major underlying factor.Dailekha (Pragatishil Samudayik Sanshtha, Ratankot) and Palpa are the major district where Jatropha is used for the operation of rice mil and tractor. In 2060/10/1 HMG/Nepal provide useless commitment for the use of $10 \%$ ethanol with the diesel to create the ecofriendly environment on their white paper. Now, at this moment Alternative Energy Promotion and different institution are engaging for the promotion of energy in Nepal. This reduced the $30 \%$ emission of carbon and the dependency ( $80 \%$ over few decades) upon the petroleum for the next generation. Sugarcane production in Terai belt and Jatropha cultivation in the Bagmati corridor can be another potential source for the production of ethanol in the country, which finally support for the people who depends upon Bagmati River for their livelihoods. Municipal wastage can be use to produce second generation biofuels, thus the crucial and targeted issues of urban areas can be resolved for urban harmonization. The wastage, thus kept may produce methane gas which has global warming

23 times relative to $\mathrm{CO}_{2}$.

\section{Current Issues in Biofuel}

\section{Production and use}

Biofuels are source for the: reduction of greenhouse gas emissions, reduction of fossil_fuel use, increased national energy security, increased rural development and a sustainable fuel supply for the future. However, the destruction of natural ecosystems whether rain forest in the tropics or grasslands in South America increases the release of greenhouse gases into the atmosphere because the ecosystems are the planet's natural sponge for carbon emissions. The process of turning plants into fuel causes emissions through refining and transport while clearance of grasslands

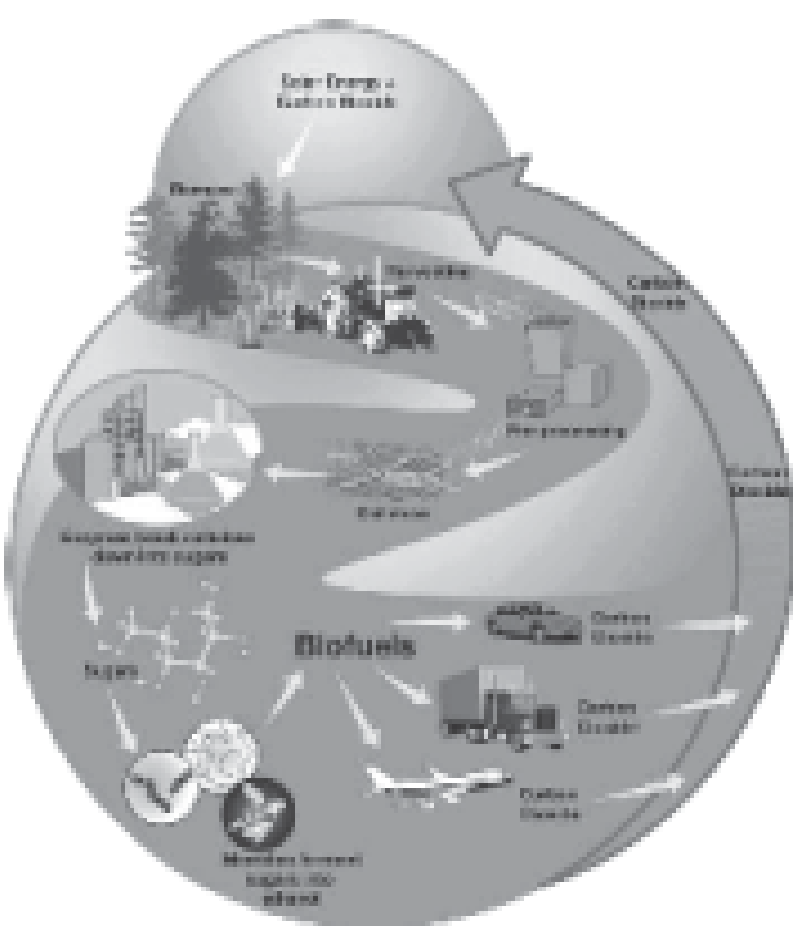

Fig.: Linking the relation of biofuels to represent the issues Source: www.google.com/biofuel/linkage 
releases 93 times the amount of green house gas that would be saved by the fuel made annually on that land ${ }^{4}$.

Purchase of biofuels leads indirectly to the destruction of natural habitats. Crops from old plantation and fields go for biofuels, but new fields and plantations are created to feed people. Presence of such trend of replacing petroleum products by the use of bio fuels and using of food crops in its production, the scarcity of food products and soaring market prices are threatening the community of less developed and developing nations. 100 million people are currently at risk due to the food price increases ${ }^{5}$. Large-scale deforestation of mature trees (which help remove $\mathrm{CO}_{2}$ through photosynthesis much better than does sugar cane or most other biofuel feedstock crops do) contributes to un-sustainable global warming atmospheric greenhouse gas levels, loss of habitat, and a reduction of valuable biodiversity ${ }^{6}$.The ligno cellulose material present in the waste material used for the preparation of ethanol then there is loss of soil nutrients which further cause soil degradation and soil erosion. However, second and third generation biofuel processes can ease the pressure on land, because they can use waste biomass, and existing (untapped) sources of biomass such as crop residues and potentially even marine algae. So if well planned and managed, biofuels market can increase the incentives and land restoration and rural development.

Increased use of biofuels puts increasing pressure on water resources in at least two ways: water use for the irrigation of crops used as feedstocks for bio diesel production; and water use in the production of biofuels in refineries, mostly for boiling and cooling.

About 860 liters of water are needed to produce one liter of ethanol. The energy balance of a biofuel is determined by the amount of energy put into the manufacture of fuel compared to the amount of energy released when it is burned in a vehicle.Biofuels save around $50 \%$ of the $\mathrm{CO}_{2}$ emissions of the equivalent fossil fuels ${ }^{7}$. This can be increased to $80-90 \% \mathrm{GHG}$ emissions savings if second generation processes or reduced fertilizer growing regimes are used.We therefore need to move towards sustainable mobility. For sustainable mobility, we can involve urban planning, improve fuel efficiency of transportation.

\section{Sustainable biofuel production}

Responsible policies and economic instruments would help to ensure that biofuel commercialization, including the development of new cellulosic technologies, is sustainable. Sustainable biofuel production practices would not hamper food and fibre production, nor cause water or environmental problems, and would actually enhance soil fertility. Responsible commercialization of biofuels represents an opportunity to enhance sustainable economic prospects in Africa, Latin America and impoverished Asia.

There is still debate on the centralized and decentralized biofuel production which effect on the local economy. Centralised vegetable oil fuel production offering efficiency, greater

\footnotetext{
4 Biofuels not so green: study,Kathmandu Post, Feb 8,2008

"Sustainable biofuels: prospects and challenges" The Royal Society (2008-01-14)

"Biofuels are not a magic bullet". www.BBC.news.np

Ethanol India website
} 
potential for fuel standardisation, ease of administrating taxes, and possibility for rapid expansion. The other side of the argument points to increased fuel security, rural job creation, less of a monopolistic or oligopolistic market due to the increased number of producers, benefit to local economy as a greater part of any profits stay in the local economy, decreased transportation and greenhouse gases of feedstock and end product, and consumers close to and able to observe the effects of production. Such crucial and targeted issues must be addressed as per required on the time.

\section{Potential for poverty reduction}

Researchers at the, Overseas Development Institute, have argued that biofuels could help to reduce poverty in the developing world, through increased employment, wider economic growth multipliers and energy price effects ${ }^{8}$. However, this potential is described as 'fragile', and is reduced where feedstock production tends to be large scale, or causes pressure on limited agricultural resources: capital investment, land, water, and the net cost of food for the poor'.

With regards to the potential for poverty reduction or exacerbation, biofuels rely on many of the same policy, regulatory or investment shortcomings that impede agriculture as a route to poverty reduction. Since many of these shortcomings require policy improvements at a country level rather than a global one, they argue for a country-by-country analysis of the potential poverty impacts of biofuels. This would consider, among other things, land administration systems, market coordination and prioritizing investment in biodiesel, as this "generates more labour, has lower transportation costs and uses simpler technology".

\section{Conclusion}

There are lots of chances around us towards the conservation of sustainable development.So, to rectified potential sources we must reform our plan, polices and program.Now, at this moment, fuel crises being popular problem for the consumer country. Despite all these facts, problem of biodiversity still there to solve which play key role in our ecosystem. Addressing the present rapid needs, can be solution for the country if we priorities the issues linking to different sector which still seeking further study like biofuel.

\footnotetext{
8 European Environment Agency (2006) How much bio energy can Europe produce without harming the environment? EEA Report no. 7

9 http://www.biodiesel.de/
} 